\title{
PERBANDINGAN PENDAPATAN USAHATANI PADI VARIETAS CIHERANG DAN MEKONGGA DI DESA ROGOMULYO
}

\author{
Marsela Anggita Ratri dan Yuliawati \\ Program Studi Agribisnis Fakultas Pertanian dan Bisnis \\ Universitas Kristen Satya Wacana, Jl. Diponegoro 52-60, Salatiga 50711 \\ Email: yuliawati.fpb@uksw.edu
}

\begin{abstract}
The purpose of this research is to (1) analyze the differences in rice farming of Ciherang and Mekongga varieties, (2) to determine $R / C$ ratio of rice farming in Ciherang and Mekongga varieties, (3) to determine the factors that influence the differences of income in rice farming between Ciherang and Mekongga varieties. This study carried out at Rogomulyo village, Kaliwungu, Semarang. Allegedly factors that affecting the differences income are seed costs, pesticide costs, fertilizer costs, labor costs, grain prices, land area and dummy varieties. The number of farmers who planted Ciherang varieties was 211 people and the number of farmers who planted Mekongga varieties was 158 people. Simple random sampling technique with a sample of 40 Ciherang varieties and 40 Mekongga rice farmers. Data collection is done through interview using questionnaires. Analysis of the data used inclued analysis of unpaired t-test (independent sample t-test), $R / C$ ratio, and multiple linier regression. The results showed that the difference in income of rice farmers of Ciherang and Mekongga varieties was Rp 1.507,056/Ha/planting season but statistically different. The $R / C$ ratio of Ciherang variety rice farming is 2,39 while the $R / C$ ratio of Mekongga varieties is 1,79. Factors that influence income differences are fertilizer costs, labor costs, grain prices, grain prices, land area and production while aeed costs, pesticidae costs, dummy varities have no effect.
\end{abstract}

Keywords : Ciherang $R / C$ ratio, Mekongga $R / C$ ratio, Income difference, Rice farming.

\section{PENDAHULUAN}

Tujuan utama pembangunan pertanian secara umum adalah untuk mensejahterakan petani, untuk itu berbagai upaya telah dilakukan oleh pemerintah khususnya dalam usahatani padi, yakni mengembangkan varietas unggul yang berdaya hasil tinggi. Deptan (1992; 2000) menyatakan melalui penggunaan benih varietas unggul dan teknik budidaya yang sesuai diharapkan produksi padi nasional dan pendapatan petani dapat ditingkatkan. Menurut Las (2004) sejak Revolusi Hijau tahun 70-an sampai sekarang, varietas unggul merupakan teknologi yang berperan dominan dalam peningkatan produksi padi dunia, sedangkan Hasanuddin (2005) menyatakan bahwa sekitar 56\% peningkatan produksi padi nasional bersumber dari penggunaan varietas unggul baru.

Sejak tahun 1930an sampai sekarang Badan Litbang Pertanian telah melepas lebih dari 200 varietas padi. Varietas yang dilepas mempunyai karakteristik yang beragam, baik varietas yang berumur genjah, produktivitas tinggi, tahan terhadap hama dan penyakit 
tertentu, dan karakter unggul lainnya. Dua varietas padi unggul yang paling banyak ditanam di Indonesia adalah Ciherang dan Mekongga. Varietas Ciherang memiliki karakteristik umur tanam cukup singkat yaitu 116 hingga 125 hari, bentuk tanaman tegak dengan tinggi mencapai 107 hingga $115 \mathrm{~cm}$, warna gabah kuning bersih dengan potensi hasil 8,5 ton/ha dan rata-rata hasil 6 ton/ha (Badan Litbang Pertanian, 2012). Padi varietas Ciherang mempunyai keistimewaan antara lain kandungan glikemik rendah yaitu 54 dan beramilosa sedang yaitu 23\%, sehingga nasinya pulen dan cocok untuk dikonsumsi oleh penderita diabetes. Varietas Ciherang juga tahan terhadap bakteri hawar daun (HDB) strain III dan IV, tahan terhadap wereng coklat biotipe 2 dan 3 (Suprihatno dkk., 2010). Varietas Mekongga merupakan persilangan antara padi jenis Galur A2970 dengan umur tanam yaitu 4 bulan yang memiliki anakan produktif 13-116 batang. Keistimewaan dari varietas ini memiliki tekstur beras yang pulen, berpotensi mencapai 8,4 ton/ha. Kemampuan benih memiliki resistensi yang cukup baik terhadap serangan hama dan penyakit seperti wereng coklat dan penyakit bakteri daun (Nurmanadi, 2012).

Kecamatan Kaliwungu merupakan daerah penghasil padi sawah urutan kedua tertinggi di Kabupaten Semarang dengan produktivitas 6,17 ton/ha (BPS Kab Semarang, 2018). Dari 11 desa yang ada di Kecamatan Kaliwungu, Desa Regomulyo merupakan desa dengan luas lahan sawah terbesar yaitu 209,44 $\mathrm{Ha}$ dengan produktivitas padi mencapai 6,85 ton/Ha/tahun. Petani di desa Rogomulyo menanam empat varietas padi yaitu Ciherang, Mekongga, IR 64, dan Bagendit. Dua varietas padi yang paling banyak ditanam adalah Ciherang dan Mekongga masing- masing sebesar $40 \%$ dan $30 \%$, sisanya menanam padi varietas IR 64 (20\%) dan Bagendit (10\%). Banyaknya petani yang menanam padi varietas Ciherang dibanding dengan varietas lainnya karena Pemerintah melalui program SL-PTT menganjurkan petani untuk menggunakan benih padi varietas Ciherang. Hasil penelitian Syamsiah dkk. (2015) menyatakan pertimbangan petani dalam menggunakan benih padi varietas unggul dipengaruhi oleh harga gabah, produktivitas, tahan terhadap hama dan penyakit serta kemudahan menjual gabah (pasar yang tersedia). Hal tersebut menandakan bahwa faktor pendapatan (potensi produksi dan harga) menjadi faktor utama dalam memutuskan menanam varietas unggul baru.

Penelitian yang mengkaji perbedaan pendapatan sebagai dampak penggunaan varietas benih padi yang digunakan belum pernah dilakukan. Penelitian-penelitian yang dilakukan umumnya lebih mengkaji sistem tanam yang dilakukan, semisal penelitian Yoshie (2010) menunjukkan meskipun tidak terdapat perbedaan yang signifikan antara pendapatan usahatani padi sawah dengan sistem tanam benih pindah dan tanam benih langsung, namun biaya pupuk, tenaga kerja dan sistem tanam berpengaruh nyata terhadap 
penerimaan pendapatan usahatani padi sawah sistem tanam pindah dan tanam benih langsung sedangkan biaya benih tidak berpengaruh nyata. Edy (2010) menunjukkan luas lahan, modal, biaya pupuk, penyuluhan berpengaruh terhadap pendapatan sedangkan biaya tenaga kerja, biaya bibit, biaya pestisida tidak berpengaruh terhadap pendapatan.

Penelitian tentang perbandingan pendapatan petani dalam penggunaan benih padi varietas unggul Ciherang dan Mekongga merupakan sesuatu hal yang sangat penting dilakukan terutama di desa Regomulyo, dimana perilaku petani akan memberikan dampak yang besar bagi Dinas Pertanian Kabupaten Semarang Jawa Tengah di dalam melaksanakan program upaya peningkatan produksi beras dan ketahanan pangan. Berdasarkan rumusan masalah yang telah dikemukakan maka tujuan penelitian ini adalah menganalisis perbedaan pendapatan usahatani padi varietas Ciherang dan Mekongga, mengetahui $\mathrm{R} / \mathrm{C}$ rasio usahatani padi varietas Ciherang dan Mekongga, dan mengetahui faktor- faktor yang mempengaruhi perbedaan pendapatan usahatani padi varietas Ciherang dan Mekongga. Ada tiga hipotesis yang diajukan yakni: (1) Diduga terdapat perbedaan pendapatan antara petani padi varietas Ciherang dan petani padi varietas Mekongga; (2) Diduga $\mathrm{R} / \mathrm{C}$ rasio usahatani padi varietas Ciherang lebih besar dari pada usahatani padi varietas Mekongga; (3) Diduga biaya benih, biaya pestisida, biaya pupuk, biaya tenaga kerja, harga gabah, luas lahan, produksi, dummy varietas berpengaruh terhadap pendapatan.

\section{METODE PENELITIAN}

\section{Waktu dan Tempat Penelitian}

Penelitian dilakukan pada bulan Maret 2018 di Desa Regomulyo, Kecamatan Kaliwungu, Kabupaten Semarang, Provinsi Jawa Tengah. Tempat penelitian dipilih secara sengaja (purposive) berdasarkan pertimbangan bahwa Desa Rogomulyo tersebut merupakan salah satu sentra produksi padi, mempunyai luas lahan sawah terbesar dan mayoritas penduduknya berprofesi sebagai petani $70 \%$.

\section{Teknik Pengambilan Contoh}

Unit analisis penelitian ini adalah petani yang berusahatani padi varietas Ciherang dan Mekongga. Populasi petani yang menanam padi varietas Ciherang sebesar 211 orang dan varietas Mekongga sebesar 158 orang. Teknik pengambilan sampel dilakukan secara acak sederhana, dengan jumlah sampel sebesar 80 orang petani, terdiri dari 40 petani padi varietas Ciherang dan 40 petani padi varietas Mekongga.

\section{Teknik Analisis Data}

Data dan informasi yang diperoleh dari hasil wawancara dengan menggunakan kuisioner, diolah, dan disajikan dalam bentuk yang lebih ringkas dan lebih mudah dipahami. Analisis data yang dilakukan yakni:

1. Analisis perbedaan pendapatan usahatani padi varietas Ciherang dan Mekongga 
Ratri dan Yuliawati, PERBANDINGAN PENDAPATAN USAHATANI...

dilakukan dengan uji beda tidak $\quad X_{3}$ : Biaya pupuk

berpasangan (Independent sample t-test)

dengan bantuan SPSS 16

$\mathrm{X}_{4} \quad$ : Biaya tenaga kerja

$\mathrm{X}_{5} \quad$ : Harga gabah

2. $\mathrm{R} / \mathrm{C}$ rasio usahatani padi varietas

$\mathrm{X}_{6} \quad$ : Luas lahan

Ciherang dan Mekongga dengan

$\mathrm{X}_{7} \quad$ : Produksi

menggunakan $\mathrm{R} / \mathrm{C}$ rasio, dengan $\mathrm{MS}$

Excel.

D : Dummy varietas $(1=$ Ciherang; $0=$

Mekongga)

Rumus :

$$
\frac{R}{C} \text { Rasio }=\frac{T R}{T C}
$$

3. Faktor- faktor yang mempengaruhi pendapatan usahatani padi varietas Ciherang dan Mekongga dianalisis menggunakan regresi linier berganda, dengan EViews 8. Model analisis menggunakan fungsi keuntungan CobbDouglass dengan logaritma natural (ln) sebagai berikut :

$\ln \mathrm{Y}=\ln \mathrm{X}_{1}+\ln \mathrm{X}_{2}+\ln \mathrm{X}_{3}+\ln \mathrm{X}_{4}+\ln \mathrm{X}_{5}+$

$$
\ln \mathrm{X}_{6}+\ln \mathrm{X}_{7}+\mathrm{D}
$$

Keterangan

Y : pendapatan usahatani padi

$\mathrm{X}_{1} \quad$ : Biaya benih

$\mathrm{X}_{2} \quad$ : Biaya pestisida

\section{HASIL DAN PEMBAHASAN}

\section{Perbedaan Pendapatan Usahatani Padi}

\section{Varietas Ciherang dan Mekongga}

Rerata pendapatan petani padi varietas Ciherang adalah Rp 11.419.342/Ha/Musim Tanam dan varietas Mekongga adalah $\mathrm{Rp}$ 9.912.286/Ha/Musim Tanam dengan selisih pendapatan sebesar Rp 1.507.056/Ha/Musim. Berarti, pendapatan petani padi varietas Ciherang lebih tinggi dibandingkan dengan pendapatan petani padi varietas Mekongga namum secara statistik tidak signifikan, ditunjukkan dari hasil uji beda pendapatan sebesar 0,351 >0,05 pada Tabel 1 :

Pendapatan yang diterima petani merupakan selisih dari penerimaan dan biaya. Hasil uji beda penerimaan sebesar 0,385 >

Tabel 1. Perbedaan Pendapatan Usahatani Padi Varietas Ciherang dan Mekongga

\begin{tabular}{lrrr}
\hline \multirow{2}{*}{ Nilai Rerata } & \multicolumn{2}{c}{ Varietas } & \multirow{2}{*}{ Uji Beda } \\
\cline { 2 - 3 } & Ciherang & \multicolumn{1}{c}{ Mekongga } & \\
\hline Pendapatan (Rp/Ha/MT) & 11.419 .342 & 9.912 .286 & 0,351 \\
Penerimaan (Rp/Ha/MT) & 21.244 .998 & 23.088 .159 & 0,385 \\
Produksi (Kg) & 4.713 & 5.269 & 0,181 \\
Harga (Rp/Kg) & 4.417 & 4.400 & 0,911 \\
Biaya (Rp/Ha/MT) & 9.825 .656 & 13.175 .873 & 0,008 \\
\hline
\end{tabular}

Sumber : Data primer diolah (2018) 
0,05 dan biaya sebesar $0,008<0,05$ dengan level signifikan $(\alpha)$ yang digunakan adalah $5 \%(0,05)$. Penerimaan dengan hasil tersebut juga berkaitan dengan perbedaan biaya yang dikeluarkan petani. Petani mengeluarkan biaya untuk pembelian benih dan pupuk namun dengan jumlah yang lebih sedikit, karena benih dan pupuk telah disubsidi oleh pemerintah. Pemerintah hanya memberikan subsidi pada petani yang menanam padi varietas Ciherang, sedangkan petani yang tidak menanam varietas Ciherang tidak mendapatkan subsidi. Setiap petani menghasilkan padi dalam bentuk gabah kering panen (GKP).

$\mathrm{R} / \mathrm{C}$ rasio pendapatan usahatani padi varietas Ciherang dan Mekongga

Analisis R/C rasio pendapatan usahatani padi varietas Ciherang dan Mekongga per hektar dapat dilihat pada Tabel 2 :

Berdasarkan hasil analisis pada Tabel 2 $\mathrm{R} / \mathrm{C}$ rasio dari kedua verietas padi di desa Rogomulyo Kecamatan Kaliwungu Kabupaten Semarang sudah efisien yaitu (R/C
>1) yang artinya bahwa usahatani tersebut layak untuk diusahakan. Nilai R/C rasio usahatani padi varietas Ciherang sebesar 2,39 artinya setiap Rp 1.000 dari biaya total yang dikeluarkan oleh petani akan memberikan penerimaan sebesar Rp 2.390 sedangkan R/C rasio pada varietas Mekongga sebesar 1,79 artinya setiap Rp.1.000 dari biaya total yang dikeluarkan oleh petani varietas Mekongga sebesar Rp1.790. Berdasarkan hasil uji beda $\mathrm{R} / \mathrm{C}$ rasio varietas Ciherang lebih besar dan berbeda nyata dibandingkan $\mathrm{R} / \mathrm{C}$ rasio varietas Mekongga. Dengan kata lain, usahatani padi varietas Ciherang lebih menguntungkan dibandingkan dengan varietas Mekongga.

Faktor- faktor yang Mempengaruhi Pendapatan Usahatani Padi Varietas

\section{Ciherang dan Mekongga}

Hasil analisis regresi linear berganda faktor- faktor yang mempengaruhi pendapatan usahatani padi varietas Ciherang dan Mekongga disajikan pada Tabel 3 :

Tabel 2. R/C rasio Usahatani Padi Varietas Ciherang dan Mekongga

\begin{tabular}{|c|c|c|c|}
\hline \multirow{2}{*}{ Nilai Rerata } & \multicolumn{2}{|c|}{ Varietas } & \multirow{2}{*}{ Uji Beda } \\
\hline & Ciherang & Mekongga & \\
\hline $\begin{array}{l}\text { Penerimaan } \\
(\mathrm{Rp} / \mathrm{Ha} / \mathrm{MT})\end{array}$ & 21.244 .998 & 23.088 .159 & 0,385 \\
\hline Biaya $(\mathrm{Rp} / \mathrm{Ha} / \mathrm{MT})$ & 9.825 .656 & 13.175 .873 & $0,008 * *$ \\
\hline $\mathrm{R} / \mathrm{C}$ & 2,39 & 1,79 & $0,001 * *$ \\
\hline
\end{tabular}

** Signifikan pada $\alpha: 0,05(5 \%)$

Sumber : Data Primer diolah (2018) 
Tabel 3. Faktor- faktor yang mempengaruhi Pendapatan Usahatani Padi Varietas Ciherang dan Mekongga

\begin{tabular}{lllll}
\hline Variabel & Coefficient & Std. Error & $t$-Statistic & Probability \\
\hline C & $-980172,0$ & 5279564, & $-0,185654$ & 0,8532 \\
LnX1 & 12,96148 & 12,00435 & 1,079732 & 0,2839 \\
LnX2 & 10,18753 & 21,73303 & 0,468758 & 0,6407 \\
LnX3 & $-11,43613$ & 2,562784 & $-4,462387$ & $0,0000^{* *}$ \\
LnX4 & $-4,229306$ & 1,979919 & $-2,136100$ & $0,0361^{*}$ \\
LnX5 & 3307,349 & 1156,498 & 2,859796 & $0,0056^{* *}$ \\
LnX6 & $-6076,593$ & 1101,984 & $-5,514230$ & $0,0000^{* *}$ \\
LnX7 & 18339,49 & 1729,422 & 10,60440 & $0,0000^{* *}$ \\
LnX8 & 771038,8 & 1551833, & 0,496857 & 0,6208 \\
\hline R-squared & 0,668702 & $\mathrm{t}$-tabel & & 1,66629 \\
Adjusted $R$-squared & 0,631373 & F-tabel & & 2,14 \\
S.E. of regression & 4357353, & & & \\
F-statistic & 17,91361 & & &
\end{tabular}

** Signifikan pada $\alpha: 0,01$ (1\%), *Signifikan pada $\alpha: 0,05(5 \%)$

Sumber: Data Primer yang Diolah, 2018

Dari hasil analisis pada Tabel 3 faktorfaktor yang mempengaruhi pendapatan usahatani padi varietas Ciherang dan Mekongga dapat ditulis dalam model sebagai berikut:

$$
\begin{gathered}
\mathrm{Y}=-980172,0+12,96148 \ln \mathrm{X} 1+1018,753 \\
\ln \mathrm{X} 2-1143,613 \ln \mathrm{X} 3-4229,306 \ln \mathrm{X} 4+ \\
3307,349 \ln \mathrm{X} 5-6076,593 \ln \mathrm{X} 6+18339,49 \\
\ln \mathrm{X} 7+771038,8 \mathrm{D}
\end{gathered}
$$

Uji ketepatan model faktor- faktor yang mempengaruhi pendapatan usahatani padi varietas Ciherang dan Mekongga berdasarkan nilai koefisien determinasi ( $R$-squared $)$ sebesar 0,668702 menunjukkan $66,87 \%$ variasi pendapatan dapat dijelaskan oleh variasi variabel bebas biaya benih (X1), biaya pestisida (X2), biaya pupuk (X3), biaya tenaga kerja (X4), harga gabah (X5), luas lahan (X6), produksi (X7), dan dummy variatas (D) sedangkan sisanya $(33,13 \%)$ dijelaskan oleh variabel lain di luar model.

Untuk mengetahui pengaruh variabel bebas secara bersama-sama terhadap variabel terikat digunakan uji F. Dari hasil analisis pada Tabel 3 diketahui nilai F-statistic 17,914 lebih besar dari Ftabel $(2,14)$ pada tingkat kesalahan $5 \%(\alpha=0,05)$ berarti variabel bebas biaya benih (X1), biaya pestisida (X2), biaya pupuk (X3), biaya tenaga kerja (X4), harga gabah (X5), luas lahan (X6), produksi 
(X7), dan dummy variatas (D) secara bersama- sama berpengaruh terhadap pendapatan usahatani padi (Y).

Pengaruh masing-masing variabel secara individual terhadap variabel terikat dapat diketahui dengan menggunakan uji $t$. Berdasarkan hasil pendugaan faktor-faktor yang mempengaruhi pendapatan usahatani padi dapat dijelaskan sebagai berikut:

1. Biaya benih tidak signifikan mempengaruhi pendapatan, hal tersebut ditunjukan dari nilai $t_{\text {hitung }} 1,079732<$ $\mathrm{t}_{\text {tabel }} 1,66629$ pada selang kepercayaan 95\%. Hasil penelitian ini sejalan dengan Yoshie (2010) bahwa biaya benih tidak signifikan terhadap peningkatan pendapatan, hal tersebut berhubungan dengan banyaknya benih dan tingkatan harga benih yang berbeda. Seperti halnya pada penelitian ini bahwa benih padi varietas Ciherang merupakan subsidi dari pemerintah sehingga biaya benih yang dikeluarkan petani menjadi berkurang, sedangkan padi varietas Mekongga tidak mendapatkan subsidi benih dari pemerintah. Riefqi (2017) menyatakan bahwa petani yang menggunakan benih padi bersubsidi mengeluarkan biaya tunai lebih rendah karena jumlah input produksi yang digunakan juga lebih rendah, sedangkan benih padi tanpa subsidi biaya yang dikeluarkan petani lebih tinggi.

2. Biaya pestisida tidak signifikan mempengaruhi terhadap pendapatan, hal tersebut ditunjukkan dari nilai $t_{\text {hitung }}$ $0,468758<\mathrm{t}_{\text {tabel }} 1,66629$ pada selang kepercayaan 95\%.. Hasil penelitian ini sesuai dengan hasil penelitian yang dilakukan oleh Edy (2010) yang menyatakan bahwa biaya pestisida tidak signifikan secara statistik terhadap pendpatan petani. Menurut Zaini (2010) juga menyatakan bahwa biaya pestisida tidak berpengaruh nyata terhadap pendapatan usahatani padi sawah.

3. Biaya pupuk signifikan mempengaruhi terhadap pendapatan, hal tersebut ditunjukkan dari nilai $\mathrm{t}_{\text {hitung }}-4,462387<$ $t_{\text {tabel }}$ 1,66629 pada selang kepercayaan 99\%. Koefisien regresi dari biaya pupuk sebesar -11,43613 menunjukkan bahwa setiap penurunan Rp 1 biaya pupuk akan mengakibatkan peningkatan pendapatan sebesar Rp 11,43613. Hal ini sejalan dengan pernyataan Edy (2010) bahwa biaya pupuk berpengaruh secara signifikan terhadap penerimaan pendapatan petani. Hasil menunjukkan bahwa biaya pupuk dapat mempengaruhi pendapatan usahatani padi varietas Ciherang dan Mekongga. Dengan adanya subsidi pupuk dari pemerintah maka petani dapat mengurangi biaya pembelian pupuk. Pupuk yang disubsidi dari pemerintah untuk padi varietas Ciherang dan Mekongga, sehingga dengan adanya penurunan biaya pupuk maka akan mempengaruhi peningkatan pendapatan usahatani padi varietas Ciherang dan 
Mekongga di desa Rogomulyo.

4. Biaya tenaga kerja signifikan mempengaruhi pendapatan, hal tersebut ditunjukkan dari nilai $t_{\text {hitung }}-2,136100<$ 1,66629 $t_{\text {tabel }}$ pada selang kepercayaan $95 \%$. Koefisien regresi dari biaya tenaga kerja sebesar -4,229306 menunjukkan bahwa setiap kenaikan Rp 1/HOK, maka akan terjadi penurunan pendapatan sebesar Rp 4,229306 Hal ini sejalan dengan penyataan Zaini (2010) bahwa biaya tenaga kerja signifikan berpengaruh nyata terhadap pendapatan usahatani padi sawah dengan adanya penggunaan tenaga kerja yang dikurangi sehingga dapat menekan biaya yang dikeluarkan. Hal tersebut sejalan dengan penelitian ini bahwa petani padi varietas Ciherang lebih banyak menggunakan biaya tenaga kerja dalam keluarga, sehingga biaya yang dikeluarkan lebih sedikit dibandingan dengan varietas Mekongga yang menggunakan biaya tenaga kerja luar keluarga.

5. Harga gabah signifikan mempengaruhi pendapatan, hal tersebut ditunjukkan dari nilai $t_{\text {hitung }} 2,859796>t_{\text {tabel }} 1,66629$ pada selang kepercayaan 99\%. Koefisien regresi dari harga gabah sebesar 3307,349 menunjukkan bahwa peningkatan harga gabah sebesar Rp 1 akan mengakibatkan peningkatan pendapatan sebesar $\mathrm{Rp}$ 3307,349. Hal ini sejalan dengan pernyataan Aprilia (2018) bahwa harga gabah berpengaruh positif dan signifikan terhadap pendapatan.

6. Luas lahan signifikan mempengaruhi pendapatan, hal tersebut ditunjukkan dari nilai $t_{\text {hitung }}-5,514230<\mathrm{t}_{\text {tabel }} 1,66629$ pada selang kepercayaan 99\%. Hal ini sejalan dengan pernyataan Zergustin dkk. (2013) bahwa luas lahan berpengaruh secara nyata terhadap pendapatan usahatani padi dengan tingkat kepercayaan 99\%. Koefisien luas lahan sebesar -6076,593 menunjukkan bahwa setiap kenaikan $1 \mathrm{~m}^{2}$, maka akan terjadi penurunan pendapatan sebesar $\mathrm{Rp}$ 6076,59. Hubungan negatif ini mengindikasikan bahwa setiap kenaikan lahan berbanding lurus dengan kenaikan biaya benih, biaya pestisida, biaya pupuk, dan biaya tenaga kerja.

7. Produksi signifikan mempengaruhi pendapatan, hal tersebut ditunjukkan dari nilai nilai $t_{\text {hitung }} 10,60440>t_{\text {tabel }} 1,66629$ pada selang kepercayaan 99\%. Koefisien produksi sebesar 18339,49 menunjukkan bahwa setiap kenaikan $1 \mathrm{~kg} / \mathrm{Ha}$. Semakin banyak produksi yang dihasilkan, maka akan mempengaruhi peningkatan pendapatan. Dengan demikian, produksi mempengaruhi pendapatan petani padi varietas Ciherang dan Mekongga.

8. Dummy varietas tidak signifikan mempengaruhi pendapatan, hal tersebut ditunjukkan dari nilai thitung $0,496857<$ $t_{\text {tabel }}$ 1,66629 pada selang kepercayaan 95\%. Sebagaimana dijelaskan pada Tabel 1 tidak ada perbedaan antara padi varietas 
Ciherang dan Mekongga dari sisi produksi, harga, penerimaan dan pendapatan. Perbedaan hanya pada biaya usahatani varietas padi Ciherang lebih rendah dibanding varietas Mekongga karena petani memperoleh subsidi benih varietas padi Ciherang dan pupuk.

\section{KESIMPULAN DAN SARAN}

\section{Kesimpulan}

Berdasarkan analisis dan pembahasan penelitian, diperoleh kesimpulan berikut :

1. Perbedaan pendapatan petani padi varietas Ciherang dan Mekongga sebesar Rp 1.507.056/Ha/Musim Tanam dan secara statistik tidak berbeda nyata

2. Nilai $\mathrm{R} / \mathrm{C}$ rasio usahatani padi varietas Ciherang sebesar 2,39 dan Mekongga sebesar 1,79

3. Faktor- faktor yang mempengaruhi pendapatan usahatani padi varietas Ciherang dan Mekongga yaitu biaya pupuk biaya tenaga kerja, harga gabah, luas lahan, dan produksi sedangkan biaya benih, biaya pestisida dan dummy varietas (D) tidak berpengaruh.

\section{Saran}

1. Bagi setiap petani dapat meminimalisir biaya pupuk, biaya tenaga kerja agar pendapatan yang diterima lebih tinggi.

2. Desa Rogomulyo dapat memberikan pengawasan dan penyuluhan secara rutin yang berkaitan dengan bantuan di setiap kelompok tani.

\section{DAFTAR PUSTAKA}

Aprilia, Mia. 2018. Pengaruh Biaya Produksi dan Harga Jual Terhadap Pendapatan Petani Menurut Perspektif Ekonomi Islam. Fakultas Ekonomi dan Bisnis Islam Universitas Islam Negeri Raden Intan Lampung.

Arikunto, S. 2010. Prosedur Penelitian Suatu Pendekatan Praktik. Jakarta: Rineka Cipta.

Badan Litbang Pertanian, 2012. Varietas Padi Unggulan Badan Litbang Pertanian. Sinar Tani Edisi 25 - 31 Januari 2012 No. 3441 Tahun XLII

BPS Kabupaten Semarang, 2018. Luas Panen, Produksi dan Produktivitas Tanaman Padi Sawah dan Padi Ladang Menurut Kecamatan di Kabupaten Semarang Tahun 2017. https://semarangkab.bps.go.id/statictab le/2015/12/17/91/luas-panen-produksidan-produktivitas-padi-sawah-danpadi-ladang-di-kabupaten-semarangtahun-2017-.html. Diakses 26 Maret 2019

Badan Pusat Statistik (BPS). Luas Wilayah dan Penggunaan Lahan Menurut Kecamatan di Kabupaten Semarang Tahun 2016.

Edy. 2010. Analisis Faktor- faktor yang Mempengaruhi Usahatani Padi Organik di Kabupaten Sragen. Surakarta.

Hasanuddin, A. 2005. Peranan proses sosialisasi terhadap adopsi varietas unggul padi tipe baru dan pengelolaannya. Lokakarya Pemuliaan Partisipatif dan Pengembangan Varietas Unggul Tipe Baru (VUTB). Sukamandi 2005.

Indah Nurhati, S. Ramdhaniati, dan N. Zuraida. Peranan dan Dominasi Varietas Unggul Baru dalam Peningkatan Produksi Pad.i di Jawa Barat. Buletin Plasma Nutfah Vol.14 No.1 Th.2008. 8-13

Kecamatan Kaliwungu Dalam Angka 2017. https://semarangkab.bps.go.id. Diakses 26 Maret 2019

Las, I. 2004. Perkembangan varietas dalam perpadian nasional. Seminar Inovasi Pertanian Tanaman Pangan. Bogor, 
Agustus 2004.

Mubyarto. 1990. Pengantar Ekonomi Pertanian.BPFE-UGM. Yogyakarta

Nurmanadi. 2012. https://ceritanurmanadi.wordpress.com/ 2012/04/26/padimekongga/. Diakses pada tanggal 12 Oktober 2018

Riefqi, Azka Radiethya. 2017. Pengaruh Benih Padi (Oryza sativa L.) Bersubsidi terhadap Produksi dan Pendapatan Petani Padi Sawah. Departemen Agronomi dan Hortikultura, Fakultas Pertanian, Institut Pertanian Bogor.

Roidah, Purnomo, S.D. 2013. Pasar Uang Dan Pasar Valas. Jakarta: PT. Gramedia Pustaka Utama.

Silvira. 2014. Analisis Faktor-Faktor yang Mempengaruhi Produksi Padi Sawah di Desa Medang, Kecamatan Medang Deras, Kabupaten Batu Bara. Fakultas Pertanian USU

Siti Syamsiah, Rita Nurmalina, Anna Fariyanti. 2015 Analisis Sikap Petani Terhadap Penggunaan Benih Padi Varietas Unggul Di Kabupaten Subang Jawa Barat. Agrise Volume XVI, No. 3, Bulan Agustus 2015. 205-215

Suprihatno, Indrasari, dan Wardana. 2010. Diskripsi Varietas Padi. Edisi Revisi. Balai Besar Penelitian Tanaman Padi. Balitbang Kementerian Pertanian. 118 hlm.

Yoshie, L.A. 2010. Perbandingan Pendapatan Usahatani Padi (Oryza zativa L.) Sawah Sistem Pindah dan Tanam Benih Langsung. Ekonomi Pertanian dan Pembangunan. Vol. 7. 30-36.

Zaini. 2010. Pengaruh Biaya Produksi dan Penerimaan Terhadap Pendapatan Petani Padi Sawah di Loa Gagak Kabupaten Kutai Kartanegara. Samarinda: Program Studi Agribisnis Fakultas Pertanian Universitas Mulawarman.

Zargustin Dedi, Siswati Latifa dan Mufti. 2013. Strata Penguasaan Lahan dan Pendapatan Usahatani Padi Sawah Serta Hubungannya dengan Alokasi Waktu Kerja di Luar Usahatani. Fakultas Pertanian Universitas Lancang Kuning Pekanbaru. 